\title{
Spatial variability of recent sedimentation in Lake Ohrid (Albania/Macedonia)
}

\author{
H. Vogel ${ }^{1}$, M. Wessels ${ }^{2}$, C. Albrecht ${ }^{3}$, H.-B. Stich ${ }^{2}$, and B. Wagner ${ }^{1}$ \\ ${ }^{1}$ Institute of Geology and Mineralogy, University of Cologne, Zülpicher Str. 49a, 50674 Cologne, Germany \\ ${ }^{2}$ Institute for Lake Research, LUBW, Argenweg 50/1, 88045 Langenargen, Germany \\ ${ }^{3}$ Department of Animal Ecology \& Systematics, Justus Liebig University Giessen, Heinrich-Buff-Ring 26-32 (IFZ), \\ 35392 Giessen, Germany
}

Received: 4 May 2010 - Published in Biogeosciences Discuss.: 25 May 2010

Revised: 8 October 2010 - Accepted: 12 October 2010 - Published: 27 October 2010

\begin{abstract}
Lake Ohrid is likely of Pliocene age and thus commonly referred to as the oldest existing lake in Europe. In this study spatial variability of recent sediment composition is assessed using $>50$ basin wide distributed surface sediment samples. Analysis of biogeochemical bulk parameters, selected metals, pigment concentrations as well as grain size distributions revealed a significant spatial heterogeneity in surface sediment composition. It implies that sedimentation in Lake Ohrid is controlled by an interaction of multiple natural and anthropogenic factors and processes. Major factors controlling surface sediment composition are related to differences in geological catchment characteristics, anthropogenic land use, and a counterclockwise rotating surface water current. In some instances processes controlling sediment composition also seem to impact distribution patterns of biodiversity, which suggests a common interaction of processes responsible for both patterns.
\end{abstract}

\section{Introduction}

Within the terrestrial realm large ancient lakes are known as favourable archives of climate and environmental change and further due to their long and often continuous existence are widely recognized as hotspots of biodiversity. Situated within the northern Mediterranean borderland, with a presumed age between five and two million years (Stankovic, 1960), and its outstanding degree of endemism (Albrecht and Wilke, 2008), Lake Ohrid constitutes a valuable archive for studies of past climate changes (e.g. Wagner et al., 2008, 2009; Vogel et al., 2010a), ash dispersal (Vogel et al., 2010b; Sulpizio et al., 2010), and forces and mechanisms of speciation (e.g. Albrecht et al., 2006; Wilke et al., 2010).

As the setting and catchment characteristics differ from lake to lake and in order to employ lacustrine sediment records as archives of climatic and environmental change thorough knowledge of modern processes and factors controlling sedimentation in each particular lake is required. Although hydrological, limnological, physical, geological as well as faunal and floral settings of Lake Ohrid have been extensively studied over the last century (Cvijic, 1911; Stankovic, 1960; Anovski et al., 1992; Watzin et al., 2002; Matzinger et al., 2006a, b, 2007; Popovska and Bonacci, 2007; Albrecht and Wilke, 2008; Wagner et al., 2008), a comprehensive survey on how these factors influence modern sedimentation in the lake and their potential impact on biodiversity patterns is still lacking.

In this study we investigated 54 spatially distributed surface sediment samples using geochemical, physical, and granulometric methods. These data is used to provide important information on processes and factors influencing sedimentation including sediment transport, sources of minerogenic and organic sediment components and in lake productivity. Moreover, possible factors controlling both sedimentation and biodiversity patterns of benthic species (e.g. Hauffe et al., 2010) across the lake are discussed.

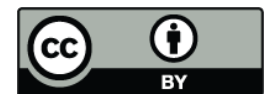

Correspondence to: $\mathrm{H}$. Vogel

(vogelh@uni-koeln.de)

Published by Copernicus Publications on behalf of the European Geosciences Union. 


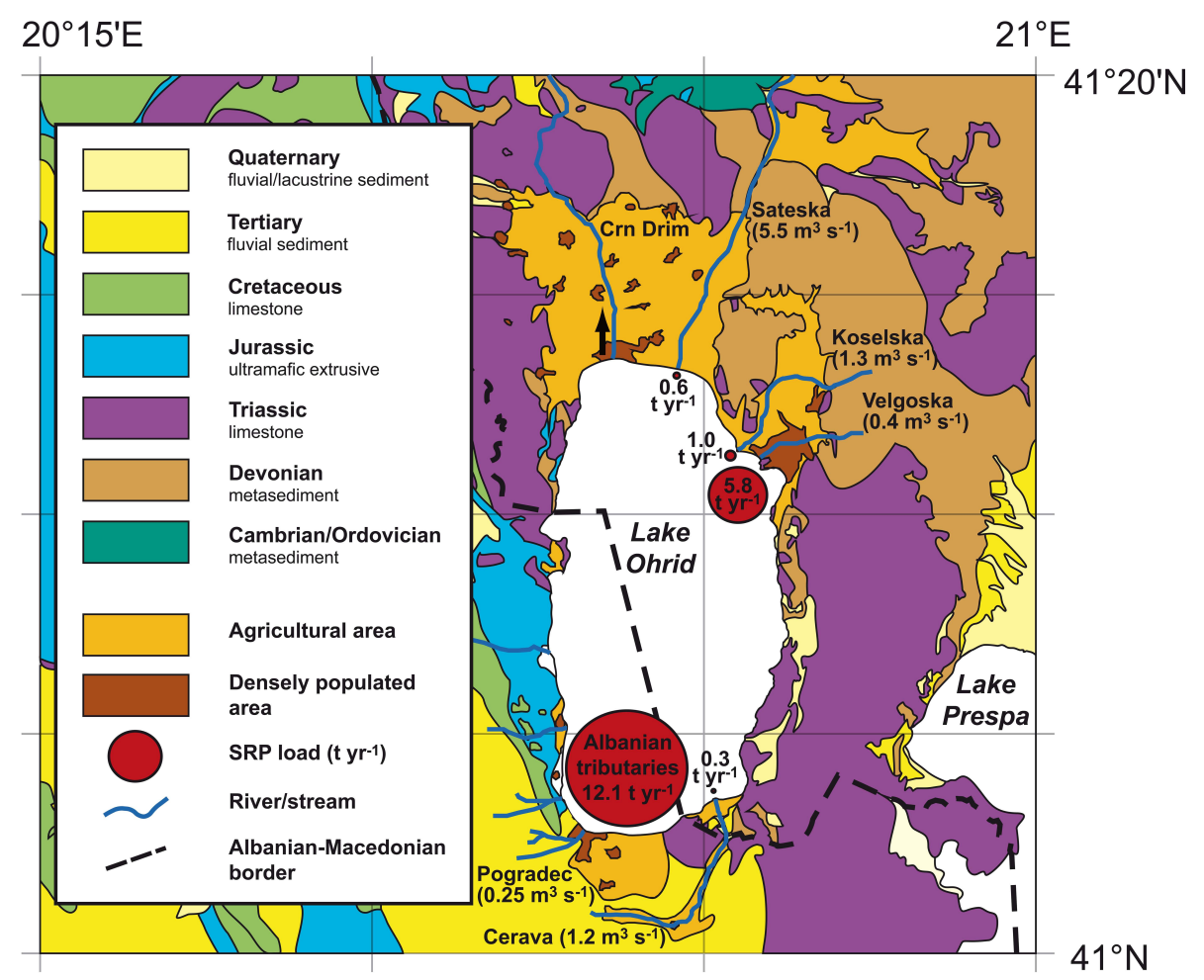

Fig. 1. Geological overview map of the Lake Ohrid vicinity on the base of accessible geological overview maps of Albania (e.g. Albanian geological survey, 1999) and Macedonia modified after Reicherter et al. (unpublished). Also shown are densely populated and agricultural areas, major streams and inlets including discharge rates (annual mean) and loads of soluble reactive phosphorus (SRP) according to Matzinger et al. (2007).

\section{Setting}

Lake Ohrid $\left(40^{\circ} 54^{\prime} \mathrm{N}-41^{\circ} 10^{\prime} \mathrm{N}, \quad 20^{\circ} 38^{\prime} \mathrm{E}-20^{\circ} 48^{\prime} \mathrm{E}\right.$; Fig. 1), a transboundary lake shared by the Republic of Albania and the Former Yugoslav Republic of Macedonia, is situated at $693 \mathrm{~m}$ a.s.l. and surrounded by high mountain ranges of up to $2300 \mathrm{~m}$ a.s.l. The lake is approximately $30 \mathrm{~km}$ long, $15 \mathrm{~km}$ wide and covers an area of $358 \mathrm{~km}^{2}$. The lake basin has a tub-shaped morphology with steep slopes on its western and eastern flanks, more gentle inclined slopes at its northern and eastern terminations, and a flat basin centre. The deepest spot is situated in the southeastern part of the flat basin and exhibits a water depth of $289 \mathrm{~m}$ (Fig. 2). The average water depth accounts to $151 \mathrm{~m}$, leading to a total volume of $50.7 \mathrm{~km}^{3}$ (Popovska and Bonacci, 2007).

The topographic watershed of Lake Ohrid comprises an area of $2393 \mathrm{~km}^{2}$ incorporating Lake Prespa, which is situated $10 \mathrm{~km}$ to the east of Lake Ohrid at an altitude of $848 \mathrm{~m}$ a.s.1. (Popovska and Bonacci, 2007; Fig. 1). The two lakes are connected by karst aquifers passing through the Galicica and Suva Gora mountain range. Karst springs depleted in nutrients and minerogenic load represent the primary hydrologic inputs to Lake Ohrid (55\%). Up to $50 \%$ of the water emerging from the inflow springs originates from Lake Prespa, with the remainder coming from precipitation on the surrounding mountain ranges (Anovski et al., 1992; Matzinger et al., 2007). Direct precipitation on the lake surface, river- and direct surface runoff together account for the remaining $45 \%$ of the hydrologic input to Lake Ohrid. Apart from temporary streams the rivers Sateska, Koselska, Cerava, Pogradec, and Verdova constitute the main riverine inflows with discharges between 0.20 (Verdova) and $5.5 \mathrm{~m}^{3} \mathrm{~s}^{-1}$ (Sateska) (Fig. 1; Watzin et al., 2002). Nutrients are primarily delivered to Lake Ohrid by surface runoff and in particular by streams which pass agricultural or densely populated areas (Matzinger et al., 2007; Fig. 1). Surface outflow (60\%) through the river Crn Drim to the north and evaporation (40\%) are the main hydrologic outputs (Matzinger et al., 2006a, b, 2007).

Complete convective mixing of the water column of Lake Ohrid only takes place roughly once per decade during severe winters when homothermy of the water body is established (Stankovic, 1960; Matzinger et al., 2006b). Wind driven convective mixing of the superficial $150-200 \mathrm{~m}$ of the water column throughout the year is, however, supported by a lack of stratification as common for deep, temperate lakes. Despite the irregular pattern of complete overturn, it is observed that dissolved oxygen (DO) concentrations remain above $6 \mathrm{mg} \mathrm{l}^{-1}$ below $200 \mathrm{~m}$ water depth throughout every year (Stankovic, 1960; Matzinger et al., 2007). Because of 


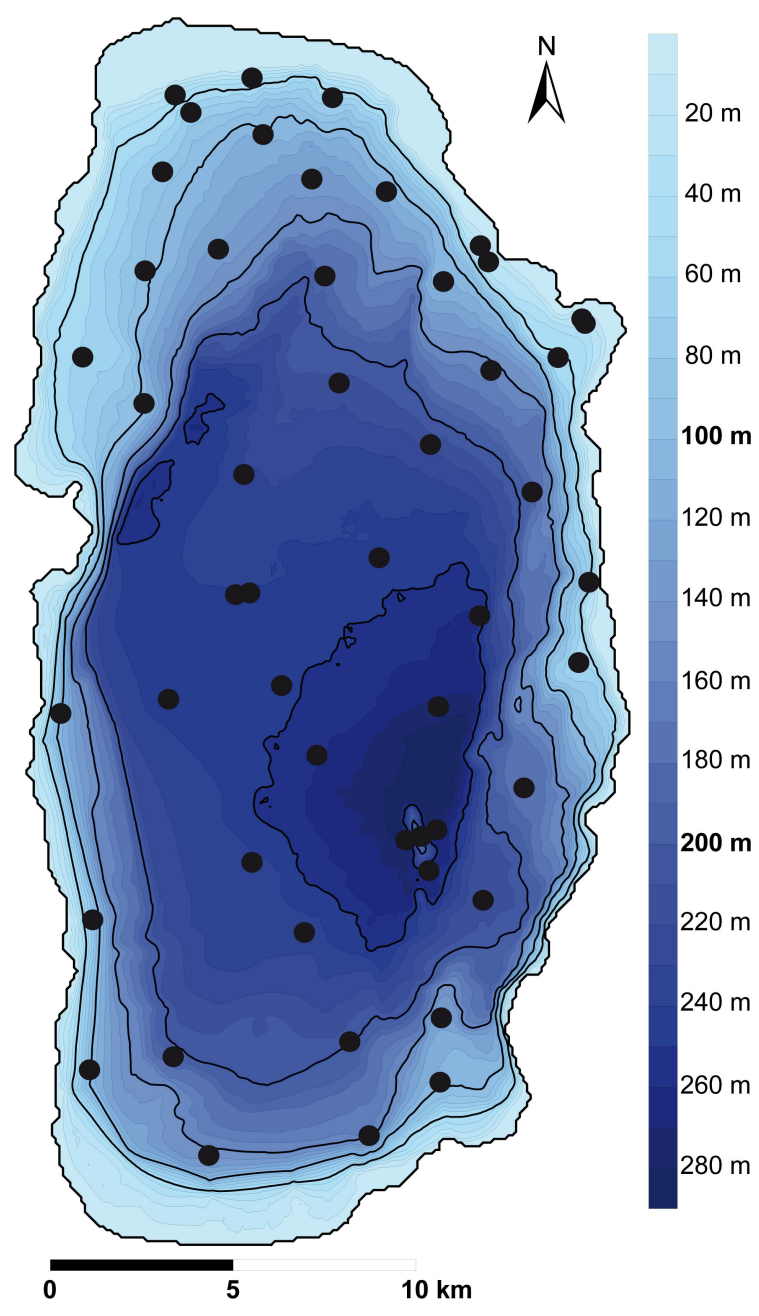

Fig. 2. Bathymetric map of Lake Ohrid with $10 \mathrm{~m}$ contour intervals. Black lines denote $50 \mathrm{~m}$ intervals (modified after Albrecht and Wilke, 2008). Black dots indicate surface sediment sampling sites.

the overall low nutrient load of the hydrologic inputs, inhibited resuspension of nutrients from the sediment-water interface by incomplete and irregular mixing of the water body, and because of its large volume, Lake Ohrid is an oligomictic and oligotrophic lake (Stankovic, 1960; Matzinger et al., 2006b; Matzinger et al., 2007).

Due to its sheltered position in a relatively deep valley surrounded by high mountain ranges and to its proximity to the Adriatic Sea, the climate of the Lake Ohrid watershed shows both Mediterranean and continental influences (Watzin et al., 2002), with an average annual air temperature for the period between $1961-1990$ of $11.1^{\circ} \mathrm{C}$; maximum temperatures below $31.5^{\circ} \mathrm{C}$; minimum temperatures above $-5.7^{\circ} \mathrm{C}$; and an average annual precipitation of 800-900 mm (Popovska and Bonacci, 2007). Prevailing wind directions follow the N-S axis of the Ohrid valley (National Severe Storms Laboratory Historical Weather Data Archives, Norman, Oklahoma, from their web site at http://data.nssl.noaa.gov).
The Ohrid valley is located within an active tectonic graben system of the Western Macedonian geotectonic zone, which is part of the interior Dinaric Alps. Metasediments of Paleozoic (Cambrian-Devonian) ages are exposed to the north and northeast of the valley. Strongly karstified limestones of Triassic age are exposed along the northwestern, eastern, and southeastern shorelines (Watzin et al., 2002). Ultramafic extrusive rocks and associated weathering crusts containing chromium and iron-nickel ore deposits of Jurassic-Cretaceous age outcrop along the southwestern and western shorelines (Dilek et al., 2007). Quaternary lacustrine and fluvial deposits occupy the plains to the north and to the south of the lake (Watzin et al., 2002; Fig. 1).

\section{Materials and methods}

\subsection{Surface sediment sampling}

During 2005 and 2007 field seasons 54 surface sediment samples were collected from representative sites all over the lake basin (Fig. 2) using the research vessel of the Hydrobiological Institute in Ohrid and a gravity corer equipped with a $6 \mathrm{~cm}$ diameter plexiglass liner. The sediment was vertically pressed out of the coring tube and the topmost $1 \mathrm{~cm}$ was sliced off. Samples were stored in a freezer prior to further processing.

\subsection{Analytical work}

All samples were freeze-dried and aliquots were ground to a particle size below $63 \mu \mathrm{m}$ using a planetary mill for subsequent geochemical analyses and X-ray-diffractometry.

Total nitrogen (TN) concentrations were measured with a Vario Micro Cube combustion CNS elemental analyzer (VARIO Co). Total carbon (TC) was detected with an infrared (IR) detector (Leco CS 125) after burning of $100 \mathrm{mg}$ sediment. In a second step, $16 \% \mathrm{HCl}$ was added to the ground sediment, $\mathrm{Cl}$-gases were trapped and $\mathrm{CO}_{2}$ was detected again with an IR detector. The amount of total organic carbon (TOC) was determined from the difference between TC and total inorganic carbon (TIC).

For analysis of $\mathrm{Al}, \mathrm{Ca}, \mathrm{Co}, \mathrm{Cr}, \mathrm{Cu}, \mathrm{Fe}, \mathrm{K}, \mathrm{Li}, \mathrm{Mg}, \mathrm{Mn}$, and $\mathrm{Ni}$ concentrations in surface sediment samples $250 \mathrm{mg}$ of sediment was treated with $8 \mathrm{ml}$ of $\mathrm{HNO}_{3}$ for $30 \mathrm{~min}$ in order to remove organic material. To dissolve the sample entirely $2 \mathrm{ml}$ of $\mathrm{HF}$ was added and samples were placed in a microwave set to $210^{\circ} \mathrm{C}$ and $1200 \mathrm{~W}$ for $24 \mathrm{~min}$. The emerged solution was neutralized using $10 \mathrm{ml} \mathrm{H}_{3} \mathrm{BO}_{4}$ and a microwave setting of $180^{\circ} \mathrm{C}$ and $1200 \mathrm{~W}$ for $25 \mathrm{~min}$. Prior to quantitative measurement of element concentrations by inductive coupled plasma optical emission spectrometry (ICPOES) using a Liberty 200 (Varian Inc.) device $50 \mathrm{ml}$ of deionized water was added in order to obtain a diluted solution. 

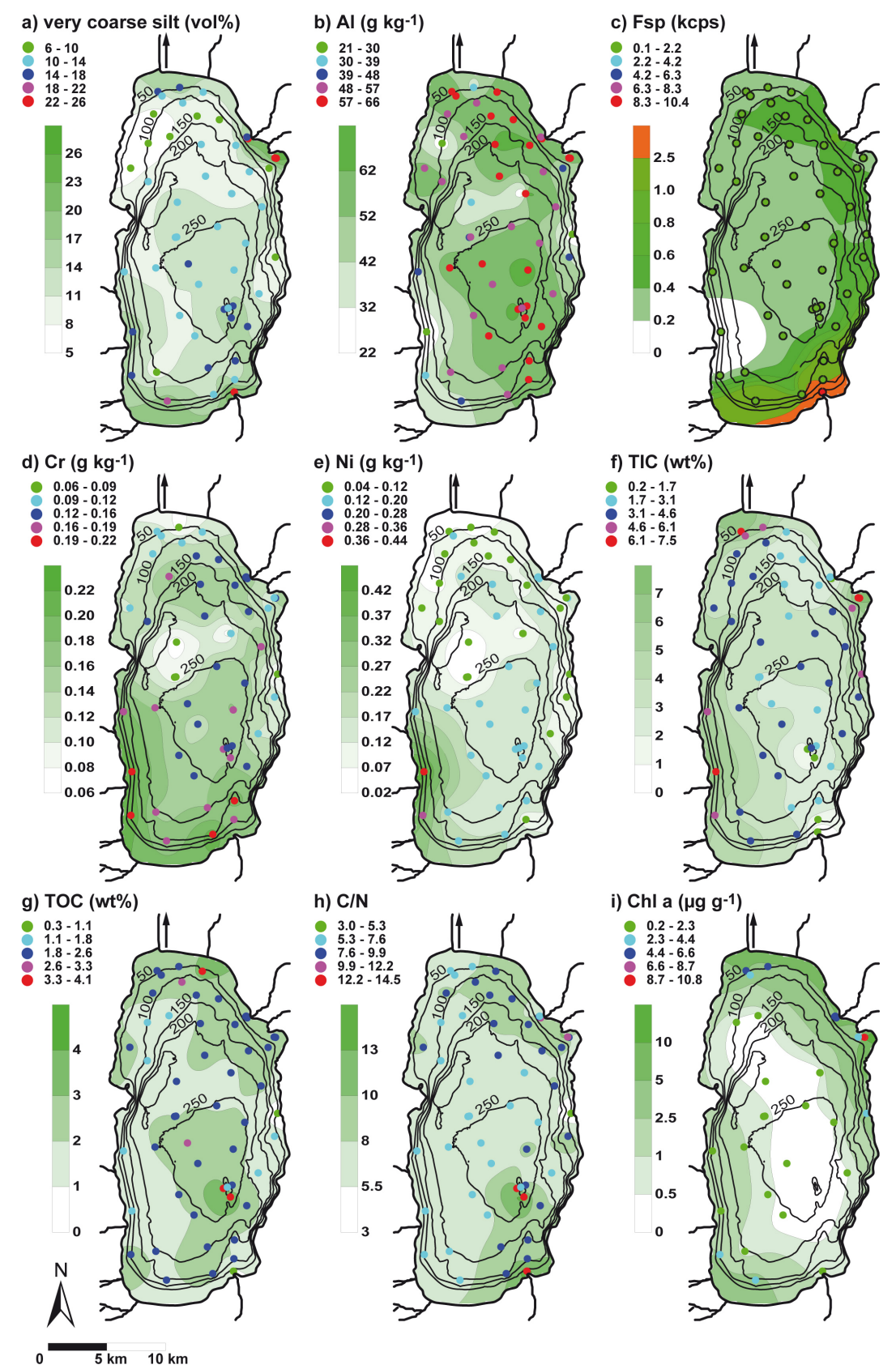

h) $\mathrm{C} / \mathrm{N}$
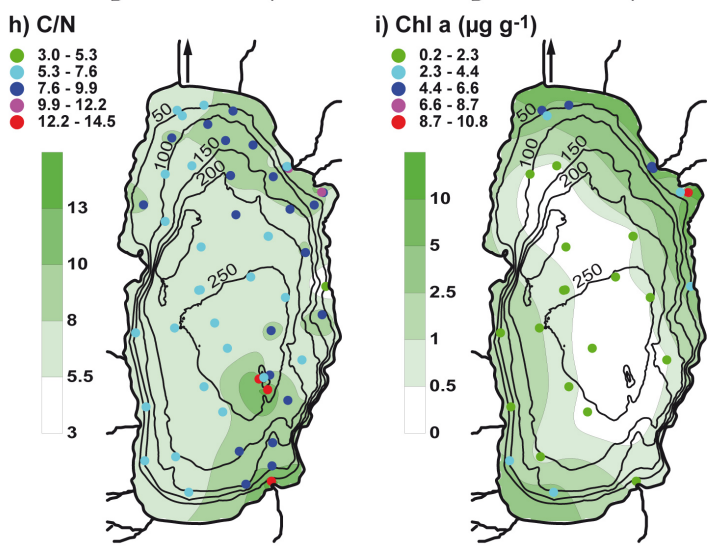

Fig. 3. Interpolated spatial distribution maps showing the concentrations of very coarse silt (a), $\mathrm{Al}$ (b), feldspar (Fsp; (c)), Cr (d), Ni (e), total inorganic carbon (TIC; (f)), total organic carbon (TOC; $(\mathbf{g})$ ), total organic carbon organic nitrogen ratio (C/N; (h)), and chlorophyll- $a$ $(\mathrm{Chl}-a$; (i)) in surface sediments of Lake Ohrid. Isopleths are interpolated using kriging and the interpolation program (SURFER v. 8). The dot legend shows sampling site specific concentration ranges and the column legend interpolated ranges.

Algal pigment concentrations were estimated using a high perfomance liquid chromatography (HPLC) device coupled to a mass spectrometer (MS) with a setup of the device and sample pre-treatment according to Schmid and Stich (1995). Included in this general overview and Fig. 3 are only results for chlorophyll- $a$, as indicator for algal biomass.
Bulk mineralogy of the sediment samples was determined with a X-Ray-diffractometer (Siemens D500) and steps of $0.05^{\circ}$ 2theta. For visualization, we used kilo counts per second (kcps). 
For grain-size analyses, $2 \mathrm{~g}$ of fresh sediment was treated with $10 \mathrm{ml} 15 \% \mathrm{H}_{2} \mathrm{O}_{2}$ to remove organic material. Subsequently, $0.3 \mathrm{~g}$ of $\mathrm{Na}_{4} \mathrm{P}_{2} \mathrm{O}_{7}$ was added to prevent flocculation of the sample. After settling of the suspension, the clear supernatant water was removed, the sediment homogenized using a spatula, and transferred to a laser-diffractometer (Micromeritics DigiSizer 5200). Half a minute of ultrasonic treatment and flow rates of $101 \mathrm{~min}^{-1}$ resuspended the sediments prior to detection. The laser-diffractometer uses a $1 \mathrm{MB}$ CCD element and calculates 160 grain size classes between 0.1 and $1000 \mu \mathrm{m}$ with the average values of two runs. Calculations of grain-size parameters and statistics were made using the program GRADISTAT (Blott and Pye, 2001). The interpolation software SURFER (8) was applied to visualize and interpolate (kriging) data.

\section{Results and discussion}

\subsection{Sources of and processes controlling the sedimentation of clastic detritus}

Grain-size distribution (Fig. 3, Supplement Fig. 1), selected metal concentrations (Fig. 3, Supplement Fig. 2), and the concentration of particular mineral phases (Fig. 3c) show a strong spatial variability in surface sediments of Lake Ohrid, which seems to be closely tied to differences in catchment geology and transport processes. These parameters can therefore yield important information on transport energies, mechanisms, and the direction of transport influencing the sedimentary composition in modern sediments of the lake.

The grain size distribution can be utilized as indicator for transport energy and flow velocity within the lake basin. With the exception of four samples taken close to riverine inlets, where sand contents range from $31-54$ vol \%, silt contents from $44-65 \mathrm{vol} \%$, and clay contents from $2-5.5 \mathrm{vol} \%$, surface sediments in Lake Ohrid at water depths of $>20 \mathrm{~m}$ (Fig. 2) generally exhibit a grain-size distribution with its maximum in the silt size fraction (78-90 vol \%) with significantly lower amounts of sand $(63-500 \mu \mathrm{m} ; 1-14 \mathrm{vol} \%)$ and clay (7-15.5 vol \%; Supplement, Fig. 1). The amount of sand sized material $>500 \mu \mathrm{m}$ is negligible. Highest amounts of fine grain-size fractions (clay-fine silt; $<2-8 \mu \mathrm{m}$ ) occur, with exceptions in shallow areas along the south-western, western, northern, and eastern shoreline, in the deeper parts of the basin (Supplement Fig. 1). In particular high amounts of clay-sized material seem to be positively correlated with greater water depths (Supplement Fig. 3), pointing to a low energy regime at greater water depths of the basin. Highest amounts of coarser grain-size fractions occur in close proximity to river mouths of the major tributaries (Supplement Fig. 1). This pattern can well be explained by higher transport energies close to riverine inlets as well as ample supply of clastic material. Coarse grain sizes (i.e. coarse silt-very fine sand; 16-125 $\mu \mathrm{m}$; Supplement Fig. 1, Fig. 3) occurring more towards the basin centre and along the coastline, not in close proximity to riverine inlets, would require a different transport mechanism such as wind induced surface currents or frequently occurring turbidity currents.

The water flow velocity required for transport of suspended coarse silt to fine sand sized clastic matter is $>0.4 \mathrm{~m} \mathrm{~s}^{-1}$ (Schäfer, 2005). This precondition for transport of coarser grained clastics, in combination with qualitative own observation of a surface water current exceeding $0.4 \mathrm{~m} \mathrm{~s}^{-1}$ in the years 2005,2007 , and 2009, imply that wind induced surface water currents could at least partly explain the observed pattern. The own observations of a surface water current are in good agreement with observations made by Stankovic (1960) in the 1940's and 1950's who observed a wind-induced surface water flow velocity exceeding $0.1 \mathrm{~m} \mathrm{~s}^{-1}$ during days with wind speeds of less than $10 \mathrm{~ms}^{-1}$.

Based on hydroacoustic data Wagner et al. (2008) described mass wasting deposits of different age primarily occurring along the steep basin slopes implying that turbidity currents as transport mechanism exist in Lake Ohrid. Turbidity currents as means of transport mechanism for coarser grain-size fractions towards the deeper parts of the lake basin require a trigger mechanism such as seismic shaking, a dynamic lake level, and/or rivers supplying sufficient amounts of clastic matter to the shelf areas of the lake. In the more recent past, a dynamic lake level (Popovska and Bonacci, 2007) or rivers supplying high amounts of clastic matter to shelf areas (Watzin et al., 2002; Matzinger et al., 2007), can likely be ruled out as triggers for mass wasting events. Steep basin slopes in combination with seismic shaking seem thus to be the most probable trigger mechanism for mass wasting events and associated turbidity currents. The last prominent earthquake $(M=6.7$; corresponding to European Macroseismic Scale X) close to the Lake Ohrid basin took place on 18th February 1911 (United States of America Geological Survey, Earthquake Database; http://earthquake.usgs.gov/earthquakes). Therefore turbidity currents triggered by prominent earthquakes could explain the occurrence of coarse silt - very fine sand in deeper parts of the lake basin. The relatively low frequency of prominent earthquakes implies, however, that transport through turbidity currents might be a rather irregularly occurring mechanism of transport.

The direction of transport in Lake Ohrid can be traced using elements from very confined catchment sources. Whereas the elements $\mathrm{Ca}, \mathrm{Co}, \mathrm{Cu}, \mathrm{Fe}, \mathrm{K}, \mathrm{Li}$, and $\mathrm{Mn}$ cannot be traced back to confined sources (Supplement Fig. 2), elements such as Al, Cr, Ni (Fig. 3), and Mg (Supplement Fig. 2g) as well as feldspar (Fig. 3c) appear to originate from very confined catchment sources. In light of the following discussion, with focus on the direction of transport and its imprint on surface sediment composition in Lake Ohrid, only the elements $\mathrm{Al}, \mathrm{Cr}, \mathrm{Ni}$, and $\mathrm{Mg}$ and the mineral phase feldspar are incorporated. 
$\mathrm{Al}$ concentrations range from 20 to $65 \mathrm{~g} \mathrm{~kg}^{-1}$ in surface sediments of Lake Ohrid. Highest concentrations are found in the northern, southeastern, and central parts of the basin. The primary source of $\mathrm{Al}$ can be traced back to the rivers Cerava, Velgoska, and Koselska, which drain Paleozoic metasediments, Triassic limestones, and Tertiary to Quaternary fluviolacustrine sediments. Input of $\mathrm{Al}$ from rivers draining ultramafic bedrock to the southwestern/Albanian part of the Ohrid catchment is significantly lower (Fig. 1; Fig. 3b). Concentrations of $\mathrm{Cr}, \mathrm{Ni}$, and $\mathrm{Mg}$ in surface sediments of Lake Ohrid range from $0.060-0.220,0.040-0.440$, and 4.8$34.2 \mathrm{~g} \mathrm{~kg}^{-1}$, respectively. As the highest concentrations can be observed in the southwestern part of the lake, it is apparent that $\mathrm{Cr}, \mathrm{Ni}$, and $\mathrm{Mg}$ primarily originate from rivers draining the southwestern part of the catchment with ultramafic bedrock and associated lateritic weathering crust exposures (Fig. 1; Fig. 3d, e; Supplement Fig. 2g). Based on the distribution of feldspar in surface sediments with highest values in close proximity to the Cerava river mouth it can be assumed that the Cerava river catchment (Fig. 1) is the most significant source of feldspar (Fig. 3c).

Apart from the highest concentration of these parameters in close proximity to their source areas further distribution seems to be connected to a common mechanism. $\mathrm{Cr}$, Ni, and to a lesser extend $\mathrm{Mg}$ are distributed from their source in the southwestern part of the lake along the southern and subsequently along the eastern shore. Northward distribution along the western shore and to the northwestern part of the lake basin seems to be negligible (Fig. 3d, e; Supplement Fig. 2g). The observed pattern of distribution could be related to grain-size effects, with enrichment of these elements in the clay fraction due to absorption on clay mineral surfaces and organic substances or incorporation in clay minerals (e.g. Boyle, 2001). A slight depletion of $\mathrm{Cr}, \mathrm{Ni}$, and $\mathrm{Mg}$ concentrations in sediments containing higher amounts of clay (Supplement Figs. 4 and 5) argues, however, against a significant influence of grain-size effects on the observed pattern. Feldspar seems to be primarily transported from its southeastern source northward following the eastern shore line (Fig. 3c). Due to the more ubiquitous occurrence of $\mathrm{Al}$ in sediments of Lake Ohrid the transport pattern as described by $\mathrm{Cr}, \mathrm{Ni}, \mathrm{Mg}$ and feldspar concentrations is not as well expressed but generally points to a northward left diverted pathway of transport (Fig. 3b).

Based on the evaluation of transport energies, mechanisms, and the direction of transport it seems as wind-driven surface currents have a strong influence on the pattern of distribution for selected components in Lake Ohrid. The indicated direction of distribution from confined sources points to a counterclockwise surface current, which has already been described for Lake Ohrid (Stankovic, 1960; Matzinger et al., 2006b) and can occasionally be observed on radar satellite images (Fig. 4). Counterclockwise surface currents have been observed in other medium to large sized lakes in the Northern Hemisphere (e.g. Beletsky et al., 1999) and can

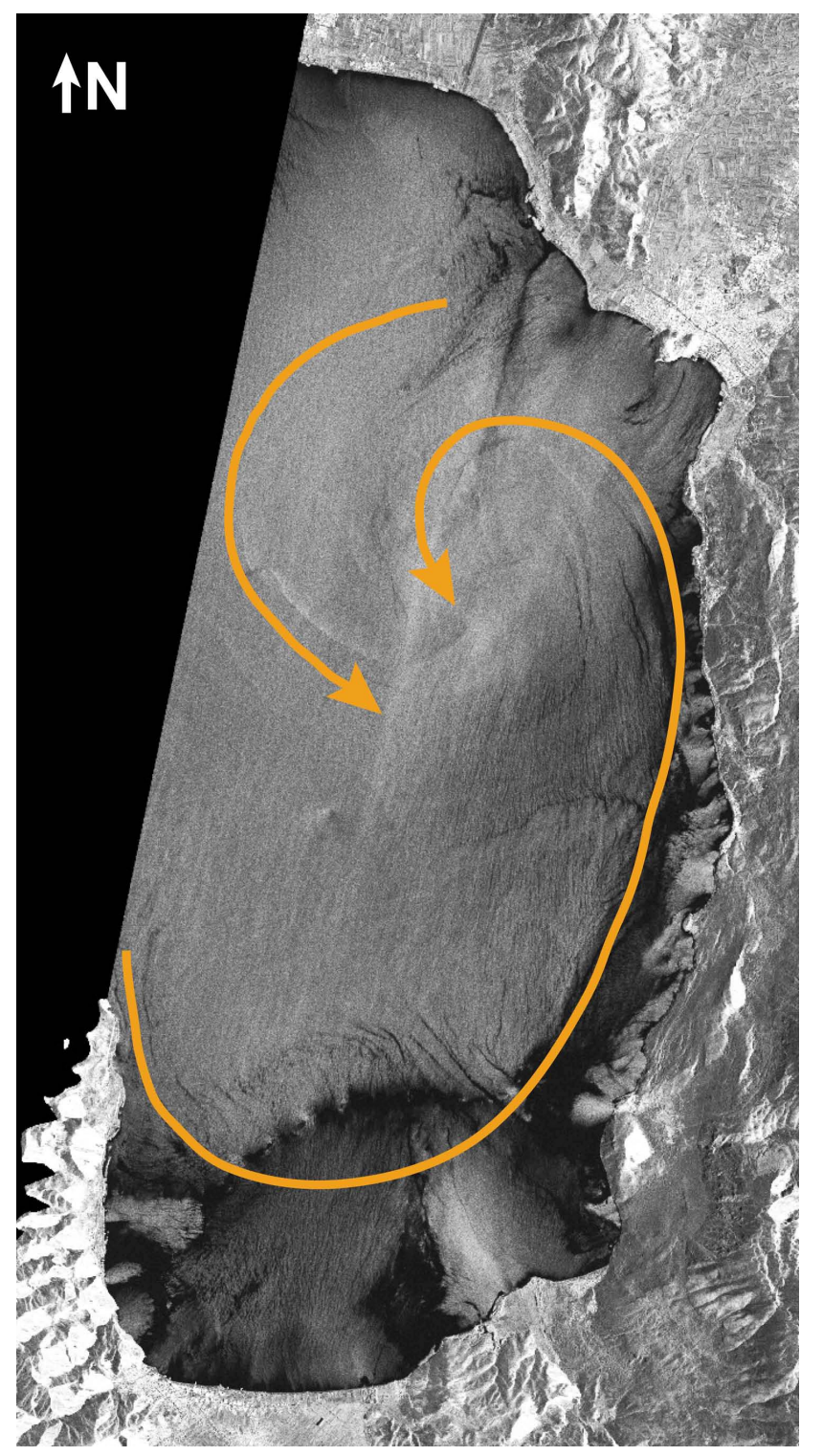

Fig. 4. Radar satellite image taken on the early morning of 30th September 2009 (ㄷ DLR 2009). Patterns seen on the water surface of Lake Ohrid probably result from differences in surface morphology (waves, currents) and/or density (suspension load, temperature). The image exhibits a counterclockwise rotating surface current with its centre in the northeastern part of Lake Ohrid. Fan-like patterns along the shoreline can probably be traced back to surface and subsurface inlets and associated differences in suspension load and water temperature. During the time the radar satellite image was taken winds were blowing from the North with a speed of $4.6 \mathrm{~m} \mathrm{~s}^{-1}$ (National Severe Storms Laboratory Historical Weather Data Archives, Norman, Oklahoma, from their web site at http://data.nssl.noaa.gov).

thus probably not be regarded as an uncommon feature in medium- to large-sized lakes such as Lake Ohrid. Bottom currents being diverted by the basin morphology could be another explanation for the observed pattern. However, taking 
the slight correlation of clay sized clastics with increasing water depths (Supplement, Fig. 3) in combination with the stratified character of the lower water column (Matzinger et al., 2006b) into account it seems rather unlikely that bottom currents contribute significantly to the observed distributional pattern. Turbidity currents triggered by earthquake induced mass wasting processes can influence surface sediment composition in Lake Ohrid. Probably due to the relatively low frequency of prominent earthquakes in the Lake Ohrid region and the rather pattern-like distribution of selected components it seems, however, that catastrophic mass movement processes did not substantially influence surface sediment composition in the most recent past.

\subsection{Factors controlling productivity and sources of organic matter}

Concentrations of TOC, TN, TIC, and chlorophyll- $a$ in surface sediments of Lake Ohrid were assessed in order to provide information on spatial differences in productivity and sources of organic matter (OM). The concentration of OM, as indicated by TOC concentrations, is relatively low in surface sediments of Lake Ohrid and shows a strong spatial variability with TOC values ranging from $0.3-4.1 \mathrm{wt} \%$ (Fig. 3). Highest TOC concentrations occur in the northern, northeastern, southwestern and central-southeastern part of the lake basin. This apparent spatial variability is probably the result of a combination of differences in catchment characteristics, anthropogenic influences, and hydrology influencing productivity and the distribution and amount of allochthonous and autochthonous OM over the lake basin.

In order to detangle variability in productivity and sources of OM, chlorophyll- $a$, related degradation products and the ratio of organic carbon and nitrogen $(\mathrm{C} / \mathrm{N})$ were inferred. Chlorophyll- $a$ concentrations ranging between 0.19 $10.8 \mu \mathrm{g} \mathrm{g}^{-1}$ as well as related degradation products such as phaeophytin- $a$ and summed pheoporbide- $a$ (not shown) are highest in the northeastern and southwestern parts of the lake basin (Fig. 3i). C/N ratios range from 3-14.5 (Fig. 3h). However, the majority of the samples analysed $(n=46)$ shows values between $6-9.8$ with only few samples showing $\mathrm{C} / \mathrm{N}$ values $>10(n=6)$ and $<6(n=2)$. Highest $\mathrm{C} / \mathrm{N}$ ratios occur at sites in close proximity to the rivers Cerava, Velgoska, and Koselska in the southeastern and northeastern parts of the lake (Fig. 1; $3 \mathrm{~h}$ ).

Strong productivity in shoreward areas of the lake can best be explained by high input of soluble reactive phosphorus (SRP), a key nutrient (Wetzel, 2001) delivered by rivers and streams passing through agricultural and/or populated areas (Fig. 1; Watzin et al., 2002; Matzinger et al., 2007). Anthropogenic land-use seems thus to be a major factor facilitating productivity at shoreward sites in close proximity to populated areas around Lake Ohrid today. The central part of the lake, in contrast, seems not to be significantly affected by nutrients originating from anthropogenic land-use, indicating that most nutrients are already used up by primary producers in shoreward areas. Upwelling in the central parts of the lake (Stankovic, 1960; Matzinger et al., 2006b), which could lead to enrichments of nutrients through recycling of OM in deeper water or at the sediment water-interface seems to be of minor importance. Traceable amounts of allochthonous OM delivered to Lake Ohrid, as indicated by $\mathrm{C} / \mathrm{N}$ ratios of $>10$ (Meyers and Ishiwatari, 1993; Meyers and Terranes, 2001), are restricted to sites close to river mouths (Fig. 3h). However, the concurrence of high TOC, low chlorophyll$a$ concentrations and $\mathrm{C} / \mathrm{N}$ ratios of up to 14 in the centralsoutheastern part of the lake basin in close proximity to the deepest spot (Fig. 3) implies a somewhat stronger contribution of allochthonous OM, potentially originating from the Cerava River. Apart from few exceptions, i.e. sites in close proximity or under the influence of riverine inlets, it can be assumed that OM in surface sediments of Lake Ohrid primarily originates from in lake productivity with only restricted contribution from terrestrial sources. Raised OM contents in surface sediments of the deeper parts of the basin (Fig. 3g) can, however, not satisfactorily be explained by strong in lake productivity (Fig. 3i) and/or increased input of allochthonous OM (Fig. 3h). Higher OM contents in these deeper parts of the lake basin might instead be due to reduced degradation as a result of inhibited oxidation in stagnant; oxygen depleted deeper water masses of Lake Ohrid (Matzinger et al., 2006b).

The amount of TIC in surface sediments of Lake Ohrid primarily originates from photosynthesis-induced calcite precipitation with only minor contribution of biogenic sources such as ostracod valves, mollusk shells, and calcite precipitated around confined subaquatic spring areas (Matter et al., 2010). The amount of detrital calcite in sediments of Lake Ohrid is negligible (Matzinger et al., 2007; Wagner et al., 2008; Vogel et al., 2010a). TIC concentrations (0.2$7.5 \mathrm{wt} \%$; Fig. 3f) are in general highest in the northern, northeastern, and southwestern parts of the lake basin and thus strongly correlated to areas with enhanced productivity (Fig. 3i). Exceptions from this general pattern comprise areas in proximity or under influence of water discharge from the Koselska and Cerava rivers (Fig. 1; Fig. 3f). Both rivers drain a widely carbonate free catchment (Fig. 1) and are thus rather depleted with respect to $\mathrm{Ca}^{2+}$ and $\mathrm{HCO}_{3}^{-}$ion concentrations. Since constant supply of $\mathrm{Ca}^{2+}$ and $\mathrm{HCO}_{3}^{-}$ions is a necessity to maintain photosynthesis-induced calcite precipitation it can be assumed that discharge from these rivers leads to a dilution of surface waters and thus the photic zone with respect to $\mathrm{Ca}^{2+}$ and $\mathrm{HCO}_{3}^{-}$ion concentrations, which in turn causes a less effective calcite precipitation. Another explanation could be dilution of calcite in the surface sediment by detrital clastic material from the Koselska and Cerava rivers (Supplement, Fig. 1). Overall the amount of endogenic calcite deposited in surface sediments of Lake Ohrid seems to be closely coupled to productivity with bias from riverine inflows depleted in $\mathrm{Ca}^{2+}$ and $\mathrm{HCO}_{3}^{-}$ion load. 


\subsection{Implications for biodiversity patterns and possible threats for endemic species}

The distribution of benthic organisms in Lake Ohrid is extremely patchy. There are both depth related and horizontal gradients in diversity distribution (Albrecht and Wilke, 2008). Differences in benthos distribution exist on small scales. Sediment structure and thus habitat characteristics are believed to correlate to the distribution of subpopulations with ecological and geographical barriers in the lake potentially promoting speciation processes. The degree of habitat patchiness is still only fragmentarily understood (Hauffe et al., 2010). It is clear, however, that habitat heterogeneity is an important component that has triggered intralacustrine evolution of endemic benthic taxa of world-wide ancient lakes (Martens, 1997).

Increased sediment loads on the other hand have repeatedly been shown to significantly reduce habitat heterogeneity resulting in decreased densities of benthic organisms (Balata et al., 2007). The impacts of increased sediment loads have been summarized by Donohue and García-Molinos (2009). It is thus interesting to observe a lowered richness of endemic molluscs in areas of highest productivity in Lake Ohrid, i.e. with the highest SRP load (Fig. 1, Fig. 3i; Hauffe et al., 2010, Fig. 4c, d). These are primarily the littoral surroundings of the inlets. Moreover, these are the areas of highest anthropogenic impact (Kostoski et al., 2010). In those areas such as the Ohrid Bay, northern, and southwestern shores, proportions of non-endemic gastropod species were highest (Hauffe et al., 2010). It is also those parts of the lake were alpha diversity is generally low. For the time being, it is exactly those disturbed littoral localities (e.g. Ohrid Bay) were non-indigenous or even alien species start to penetrate the lake proper (Kostoski et al., 2010).

Highly disturbed stretches exist along the western Albanian shore and $\mathrm{Cr}$ and $\mathrm{Ni}$ input are known to be enhanced by the mining facilities there (Watzin et al., 2002). Toxic effects and bioaccumulation tendencies of those trace metals are well known (e.g. Paquin et al., 2003; Kiffney and Clements, 2003), not yet studied in Lake Ohrid but demonstrated in other Balkan large lakes such as Lake Vegoritis (Skoulikidis et al., 2008).

It has been shown that an oligotrophic status is an important predictor for high mollusc diversity and endemicity in world-wide ancient lakes. Signs of eutrophication as indicated in this study as well as hydrological assessments (Matzinger et al., 2006b, 2007) are important signals towards changes in the lakes ecosystem. Such a trend would have a multitude of consequences for biodiversity with effects ranging from biofilm changes and changing plankton communities and eventually to interrupted food chains. Other Balkan ancient and potentially ancient lakes have already experienced such recent anthropogenically induced ecosystem changes (e.g. Albrecht et al., 2009). Related oxygen depletion in sediments, mechanic abrasion, and clogging in- terstices threaten particular habitat types to which many endemic species have specifically adapted. One such particular habitat of Lake Ohrid is the so-called sublacustrine interlithon (Albrecht and Wilke, 2008). The increased silt loads combined with the identified prevailing counterclockwise direction of the surface current may present a threat to this Ohrid specific habitat and the associated biodiversity hotspot (Hauffe et al., 2010) on the southeastern shore of the lake. Alteration to habitat structure and reduced habitat quality in general have been hypothesized to pose a major threat to the survival of Lake Ohrid endemic species (Kostoski et al., 2010). Changes in the sediments are directly or indirectly effecting most benthic organisms. This real or near-future threat is most severe for small-range endemics in many of the benthic taxa of the lake.

\section{Conclusions}

The investigation of $>50$ basin wide distributed surface sediment samples yielded important information on modern sedimentation in Lake Ohrid. According to our investigations surface sediment composition varies significantly due to differing influences of catchment geology, anthropogenic land use and transport processes.

Based on the grain-size distribution pattern, relatively strong wind driven surface currents were identified as the main transport process in Lake Ohrid. Bottom and turbidity currents seem to be of minor importance. Differences in the surrounding catchment geology have a strong impact on surface sediment composition and can be traced using $\mathrm{Al}$, $\mathrm{Cr}, \mathrm{Ni}, \mathrm{Mg}$, and feldspar concentrations. Due to the known sources of these components an observable counterclockwise rotating surface current can best explain the direction of transport of suspended clastic matter in Lake Ohrid.

The distribution of TOC, TN, and pigment concentrations over the lake basin revealed that organic matter in surface sediments of Lake Ohrid primarily originates from in lake productivity. Areas with highest productivity are situated in close proximity to riverine inlets with high SRP load originating from the drainage of agricultural and/or densely populated areas in the catchment. Nutrient load from these inlets seems to have only limited impact on productivity in more distal and basinward sites of Lake Ohrid.

Small-scale differences in sediment composition might have been responsible for habitat patchiness in related substructuring of predominantly benthic communities. Such heterogeneities might also be linked to evolutionary processes such as speciation. On the other hand, anthropogenic interference in sedimentation processes and particularly pollution with nutrients but also trace metals is believed to pose real threats to the primarily benthic endemic biodiversity of Lake Ohrid. Circumstantial evidence hints towards an already existing decline in habitat structure and species abundances. Conservation measures should therefore also focus 
on reducing anthropogenic effects on ecosystem processes such as sedimentation.

\section{Supplementary material related to this article is available online at: http://www.biogeosciences.net/7/3333/2010/ bg-7-3333-2010-supplement.pdf.}

Acknowledgements. The fieldwork was supported through great logistic support by the Hydrobiological Institute in Ohrid. An earlier version of the manuscript has benefitted greatly from the constructive review of A. Dehnert and another anonymous reviewer. This research was supported by DFG grants to BW (WA2109/1-1) and CA (AL 1076/3-1).

Edited by: T. Wilke

\section{References}

Albanian geological survey: Geological and mineral deposit map of Albania, 1:200,000, 1999.

Albrecht, C., Trajanovski, S., Kuhn, K., Streit, B., and Wilke, T.: Rapid evolution of an ancient lake species flock: freshwater limpets (Gastropoda: Ancylidae) in the Balkan lake Ohrid, Organisms, Diversity and Evolution, 6, 294-307, 2006.

Albrecht, C. and Wilke, T.: Ancient Lake Ohrid: biodiversity and evolution, Hydrobiol., 615, 103-140, 2008.

Albrecht, C., Hauffe, T., Schreiber, K., Trajanovski, S., and Wilke, T.: Mollusc biodiversity and endemism in the potential ancient Lake Trichonis (Greece), Malacologia, 51, 357-375, 2009.

Anovski, T., Andonovski, B., and Minceva, B.: Study of the hydrological relationship between Lake Ohrid and Prespa. Proc Symp Isotope Techn Water Res Dev. IAEA, Vienna, Austria, March 1991, 1992.

Balata, D., Piazzi, L., and Benedetti-Cecchi, L.: Sediment disturbance and loss of beta diversity on subtidal rocky reefs, Ecology, 88, 2455-2461, 2007.

Beletsky, D., Saylor, J. H., and Schwab, D. J.: Mean circulation in the Great Lakes, J. Great Lakes Res., 25, 78-93, 1999.

Blott, S. J. and Pye, K.: Gradistat: A grain-size distribution and statistics package for the analysis of unconsolidated sediments, Earth Surf. Process. Landforms, 26, 1237-1248, 2001.

Boyle, J. F.: Inorganic geochemical methods in paleolimnology, in: Tracking Environmental Change Using Lake Sediments, edited by: Last, W. M. and Smol, J. P., Volume 2 Physical and Geochemical Methods, 83-141, Dordrecht, Kluwer, 2001.

Cvijic, J.: L'ancient Lac Égéen, Ann. Geographicae, 20, 233-259, 1911.

Dilek, Y., Furnes, H., and Shallo, M.: Suprasubduction zone ophiolite formation along the periphery of Mesozoic Gondwana, Gondw. Res., 11, 453-475, 2007.

Donohue, I. and García-Molinos, J.: Impacts of increased sediment loads on the ecology of lakes, Biol. Rev., 84, 517-531, 2009.

Hauffe, T., Albrecht, C., Schreiber, K., Birkhofer, K., Trajanovski, S., and Wilke, T.: Spatially explicit analyses of gastropod biodiversity in ancient Lake Ohrid, Biogeosciences Discuss., 7, 49534985, doi:10.5194/bgd-7-4953-2010, 2010.
Kiffney, P. M. and Clements, W. H.: Ecological effects of metals on benthic invertebrates, in: Biological response signatures: indicator patterns using aquatic communities, edited by: Simon, T. P., CRC Press, Boca Raton, FL, 135-154, 2003.

Kostoski, G., Albrecht, C., Trajanovski, S., and Wilke, T.: A freshwater biodiversity hotspot under pressure - assessing threats and identifying conservation needs for ancient Lake Ohrid, Biogeosciences Discuss., 7, 5347-5382, doi:10.5194/bgd-7-5347-2010, 2010.

Martens, K.: Speciation in ancient lakes, Trends Ecol. Evol. (Amst.), 12, 177-182, 1997.

Matter, M., Anselmetti, F. S., Jordanoska, B., Wagner, B., Wessels, M., and Wüest, A.: Carbonate sedimentation and effects of eutrophication observed at the Kalita subaquatic springs in Lake Ohrid (Macedonia), Biogeosciences Discuss., 7, 47154747, doi:10.5194/bgd-7-4715-2010, 2010.

Matzinger, A., Jordanoski, M., Veljanoska-Sarafiloska, E., Sturm, M., Müller, B., and Wüest, A.: Is Lake Prespa jeopardizing the ecosystem of ancient Lake Ohrid? Hydrobiologica, 553, 89-109, 2006a.

Matzinger, A., Spirkovski, Z., Patceva, S., and Wüest, A.: Sensitivity of ancient Lake Ohrid to local anthropogenic impacts and global warming, J. Great. Lakes Res., 32, 158-179, 2006 b.

Matzinger, A., Schmid, M., Veljanoska-Sarafiloska, E., Patceva, S., Guseska, D., Wagner, B., Müller, B., Sturm, M., and Wüest, A.: Eutrophication of ancient Lake Ohrid: Global warming amplifies detrimental effects of increased nutrient inputs, Limnol. Oceanogr., 52, 338-353, 2007.

Meyers, P. A. and Ishiwatari, R.: Lacustrine organic geochemistry - an overview of indicators of organic matter sources and diagenesis, Org. Geochem., 20, 867-900, 1993.

Meyers, P. A. and Terranes, J. L.: Sediment Organic Matter, in: Tracking Environmental Change Using Lake Sediments, edited by: Last, W. M. and Smol, J. P., Volume 2 Physical and Geochemical Methods, 239-269, Dordrecht, Kluwer, 2001.

Paquin, P. R., Di Toro, D. M., Farley, K., Santore, R. C., and Wu, K.B.: Metals in Aquatic Systems: A Review of Exposure, Bioaccumulation, and Toxicity Models, SETAC Foundation, 2003.

Popovska, C. and Bonacci, O.: Basic data on the hydrology of Lakes Ohrid and Prespa, Hydrol. Proc., 21, 658-664, 2007.

Schäfer, A.: Klastische Sedimente: Fazies und Sequenzstratigraphie, Elsevier Gmbh, Spektrum Akademischer Verlag, München, Germany, 2005.

Schmid, H. and Stich H. B.: HPLC - analysis of algal pigments: Comparison of columns, column properties and eluents, J. Appl. Phycol., 7, 487-494, 1995.

Skoulikidis, N., Kaberi, H., and Sakellariou, D.: Patterns, origin and possible effects of sediment pollution in a Mediterranean lake, Hydrobiologia, 613, 71-83, 2008.

Stankovic, S.: The Balkan Lake Ohrid and its living world, Monographiae Biologicae IX, Dr. W. Junk, Den Haag, The Netherlands, 1960.

Sulpizio, R., Zanchetta, G., D’Orazio, M., Vogel, H., and Wagner, B.: Tephrostratigraphy and tephrochronology of lakes Ohrid and Prespa, Balkans, Biogeosciences, 7, 3273-3288, doi:10.5194/bg-7-3273-2010, 2010.

Vogel, H., Wagner, B., Zanchetta, G., Sulpizio, R., and Rosén, P.: A paleoclimate record with tephrochronological age control for the last glacial-interglacial cycle from Lake Ohrid, Albania and 
Macedonia, J. Paleolimnol., 44, 295-310, 2010a.

Vogel, H., Zanchetta, G., Sulpizio, R., Wagner, B., and Nowaczyk, N.: A tephrostratigraphic record for the last glacial-interglacial cycle from Lake Ohrid, Albania and Macedonia, J. Quat. Sci., 25, 320-338, 2010b.

Wagner, B., Lotter, A. F., Nowaczyk, N., Reed, J. M., Schwalb, A., Sulpizio, R., Valsecchi, V., Wessels, M., and Zanchetta, G.: A 40,000-year record of environmental change from ancient Lake Ohrid (Albania and Macedonia), J. Paleolimnol., 41, 407-430, 2009.

Wagner, B., Reicherter, K., Daut, G., Wessels, M., Matzinger, A., Schwalb, A., Spirkovski, Z., and Sanxhaku, M.: The potential of Lake Ohrid for long-term palaeoenvironmental reconstructions, Palaeogeogr. Palaeoclimatol. Palaeoecol., 259, 341-356, 2008.
Watzin, M. C., Puka, V., and Naumoski, T. B.: Lake Ohrid and its watershed, state of the environment report, Lake Ohrid Conservation Project, Tirana, Republic of Albania and Ohrid, Republic of Macedonia, 2002.

Wetzel, R. G.: Limnology, Academic Press, San Diego, USA, London, UK, 2001.

Wilke, T., Schultheiß, R., Albrecht, C., Bornmann, N., Trajanovski, S., and Kevrekidis, T.: Native Dreissena freshwater mussels in the Balkans: in and out of ancient lakes, Biogeosciences, 7, 3051-3065, doi:10.5194/bg-7-3051-2010, 2010. 